\title{
KORELASI PENERAPAN GERAKAN LITERASI SEKOLAH (GLS) DENGAN KEMAMPUAN MENYELESAIKAN SOAL CERITA MATEMATIKA SISWA DI SDN KEBONDALEM MOJOSARI DAN SDN KETABANG SURABAYA
}

\author{
Susi Hermin Rusminati ${ }^{1)}$, Cholifah Tur Rosidah ${ }^{2)}$ \\ PGSD Universitas PGRI Adi Buana Surabaya ${ }^{1)}$, PGSD Universitas PGRI Adi Buana \\ Surabaya ${ }^{2)}$ \\ susiherminr@unipasby.ac.id ${ }^{1)}$, cholifah@unipasby.ac.id ${ }^{2)}$
}

\begin{abstract}
Abstrak
Penelitian ini bertujuan untuk mengetahui korelasi antara Gerakan Literasi Sekolah (GLS) dengan kemampuan menyelesaikan soal cerita matematika siswa di SDN Kebondalem Mojosari dan SDN Ketabang Surabaya. Penelitian ini didasarkan atas observasi pada keminatan peserta didik dalam menyelesaikan soal cerita matematika yang sering kali merasa malas membaca, sehingga mengalami kesulitan memahami maksud dari bacaan yang tersaji pada soal cerita. Adapun target luaran yang ingin dicapai dalam penelitian ini berupa (1) artikel ilmiah dalam jurnal nasional terakreditasi, (2) draf buku ajar. Metode yang digunakan untuk mencapai tujuan dan target tersebut adalah metode kuantitatif. Dalam proses pelaksanaannya penelitian ini melalui beberapa tahapan antara lain (1) tahap awal yaitu pengurusan ijin, penentuan populasi dan sampel, perancangan instrumen, dan perancangan soal cerita matematika, (2) tahap pelaksanaan, meliputi penentuan sampel, pemberian soal cerita, (3) tahap analisis data, dan (4) tahap pelaporan. Hasil penelitian di SDN. Ketabang Surabaya menunjukkan bahwa $r_{\text {hitung }}(0,517)>r_{\text {tabel }}(0,3291)$ dan SDN. Kebondalem Mojokerto adalah $r_{\text {hitung }}(0,667)>r_{\text {tabel }}(0,3739)$ dengan kesimpulan adanya korelasi Gerakan Literasi Sekolah (GLS) dengan kemampuan siswa menyelesaikan masalah soal cerita matematika.
\end{abstract}

Kata Kunci: Korelasi, Literasi, Soal Cerita Matematika

\begin{abstract}
This research aims to know the correlation between Gerakan Literasi Sekolah (GLS) with the ability to solve math story problem students at SDN Kebondalem and Mojosari SDN Ketabang Surabaya. The study is based on observations at keminatan students in solving math story problem that often feel lazy to read, so have difficulty understanding the meaning of the readings are presented in the matter of the story. As for the external targets to be achieved in this research in the form of (1) scientific articles in national journals (2) accredited, draft textbook. The methods used to achieve these goals and targets is a quantitative method. In the process of implementation of this research through several stages, among others, (1) the early stages namely management of permissions, determining the population and sample, the design of the instrument, and designing a math story problem, (2) the stage of implementation, including the determination of samples, awarding a matter story, (3) the stage of data analysis, and (4) a reporting phase. Research results on SDN. Ketabang Surabaya showed that $r_{\text {hitung }}(0,517)>r_{\text {tabel }}(0,3291)$ dan SDN. Kebondalem Mojokerto adalah $r_{\text {hitung }}(0,667)>r_{\text {tabel }}(0,3739)$ with the conclusion of the existence of the correlation of Gerakan Literasi Sekolah (GLS) and students ability to resolve problems with math story problem.
\end{abstract}

Keywords: Correlation, Literacy, Math Story Problem 


\section{Pendahuluan}

Membangun negara seyogyanya memperhatikan kualitas sumber daya manusia karena sumber daya yang berkualitas menjadi tumpuan agar suatu bangsa dapat berkompetisi. Pendidikan merupakan titik tumpu kemajuan bangsa, oleh karena itu pemerintah selalu berupaya untuk kemajuan pendidikan di Indonesia. Salah satu upaya pemerintah untuk pendidikan ialah dengan menggagas Gerakan Literasi Sekolah abad-21 atau yang disingkat dengan GLS.

GLS telah diluncurkan oleh Kemendikbud pada bulan Februari 2016 (Kompasiana: 2016). GLS yang sedang didengung-dengungkan saat ini merupakan gerakan sosial dengan dukungan kolaboratif berbagai elemen. Istilah "literasi" mempunyai makna yang luas, tidak terbatas pada membaca dan menulis saja, tetapi literasi dimaknai implikasi dari keterampilan membaca dan menulis dasar ke perolehan dan manipulasi pengetahuan melalui teks tertulis, dari analisis metalinguistik unit gramatikal ke struktur teks lisan dan tertulis.

Proses memahami bacaan tidaklah mudah, seperti yang dikatakan Kintsch \& Kintsch dalam Fathani (2016) proses memahami bacaan bukan merupakan proses yang sederhana. Sejalan dengan pendapat tersebut Caldwell dalam Fathani (2016) menjelaskan "reading is an extremely complex and multifaceted process". Namun, proses memahami bacaan yang kompleks tersebut dapat dilakukan oleh pembaca yang secara aktif terlibat dalam proses secara simultan. Untuk membantu proses pembangunan generasi yang literat tersebut, GLS yang telah berjalan selama dua tahun ini diimplementasikan melalui pembiasaan membaca selama 15 menit sebelum pembelajaran dimulai. Dengan harapan setelah pembiasaan terbentuk, selanjutnya akan diarahkan pada tahap pengembangan dan pembelajaran dengan variasi kegiatan berupa perpaduan pengembangan ketrampilan reseptif maupun produktif.

Salah satu muatan pelajaran di Sekolah Dasar yang membutuhkan pemahaman, penalaran, dan keterampilan dalam proses penyelesaiannya adalah matematika. Undang-Undang RI Nomor 20 Tahun 2003 tentang Sistem Pendidikan Nasional pasal 37 menegaskan bahwa matematika merupakan salah satu mata pelajaran wajib bagi siswa sekolah pada jenjang pendidikan dasar dan menengah. Evaluasi tingkat keberhasilan pembelajaran matematika dapat dilihat dari prestasi ditingkat Nasional maupun Internasional. Di level nasional tingkat keberhasilan biasa dilihat dari hasil Ujian Nasional maupun Ujian Sekolah, sedangkan pada level Internasional terdapat dua asesmen utama yang menilai kemampuan matematika dan sains siswa yaitu TIMSS (Trend in International Mathematics and Science Study) dan PISA (Program for International Student Assesment).

TIMSS diselenggarakan empat tahun sekali secara regular sejak tahun 1994/1995 guna mengetahui pencapaian siswa dalam matematika dan sains. TIMSS fokus pada materi yang tercakup dalam kurikulum, seperti bilangan, pengukuran, aljabar, geometri, dan data. Sedangkan PISA diselenggaran tiga tahun sekali secara regular sejak tahun 2000 untuk mengetahui literasi siswa dalam matematika, sains, dan membaca. PISA fokus pada literasi yang menekankan pada keterampilan dan kompetensi siswa yang diperoleh dari sekolah dan dapat diimplementasikan dalam kehidupan di berbagai situasi (Johar: 2012). Hal itu sesuai dengan standar isi muatan pelajaran matematika yang bertujuan agar siswa memiliki kemampuan memahami, menggunakan penalaran, memecahkan masalah, mengomunikasikan dan memiliki sikap 
menghargai matematika (Permendiknas: 2006).

Tujuan pembelajaran matematika tersebut dapat diimplemantasikan pada pemecahan masalah soal cerita. Soal cerita memuat banyak kosa kata dan teks yang memerlukan analisis, penalaran dan pemahaman. Namun, kenyataan di lapangan, justru banyak siswa merasa malas dan bosan ketika dihadapkan dengan soal cerita. Hal ini karena kurangnya keterampilan menalar siswa untuk dapat memecahkan masalah.

Berdasarkan fakta dan permasalahan tersebut maka penulis melakukan penelitian tentang "Hubungan Antara Pemanfaatan Gerakan Literasi Sekolah dengan Kemampuan Menyelesaikan Soal Cerita Matematika Siswa Sekolah Dasar".

\section{a. Hakikat Literasi}

Literasi merupakan kemampuan berbahasa seseorang yang terlihat dalam berbagai kegiatan seperti membaca, menulis, menyimak, dan berbicara untuk berkomunikasi dengan cara yang berbedad seesuai dengan tujuannya. Adapun makna literasi dalam arti sempit ialah literasi sebagai kemampuan untuk membaca dan menulis (able to read and write). Namun, dalam buku panduan GLS di SD dijelaskan bahwa literasi tidak hanya terbatas pada membaca dan menulis melainkan literasi adalah kemampuan mengakses, memahami, dan menggunakan sesuatu secara cerdas melalui berbagai aktivitas membaca, menyimak, menulis dan/ atau berbicara.

\section{b. Tujuan Gerakan Literasi Sekolah}

Tujuan GLS secara umum adalah untuk menumbuhkembangkan budi pekerti peserta didik melalui pembudayaan ekosistem literasi sekolah yang diwujudkan dalam GLS agar mereka menjadi pembelejar sepanjang hayat.
Sedangkan, secara khusus GLS dilaksanakan untuk menumbuhkembangkan budaya literasi di sekolah, meningkatkan kapasitas warga dan lingkungan sekolah yang literat, menjadikan sekolah sebagai taman belajar yang mampu mengelola pengetahuan dengan menyenangkan dan ramah anak, serta menjaga keberlanjutan pembelajaran dengan menghadirkan beragam bacaan dan mewadahi berbagai strategi membaca.

\section{c. Tahapan Gerakan Literasi Sekolah di SD}

Pelaksanaan GLS di SD dilakukan secara bertahap meliputi tahap pembiasaan, tahap pengembangan, dan tahap pembelajaran. Tahap pembiasaaan dilakukan dengan tujuan penumbuhan minat baca siswa yang dilaksanakan melalui kegiatan 15 menit membaca sebelum pembelajaran dimulai (Permendikbud No.23 Tahun 2015). Selanjutnya tahap pengembangan dilakukan dengan tujuan meningkatkan kemampuan literasi melalui kegiatan mennaggapi buku pengayaan. Dan tahapan terakhir ialah tahap pembelajaran yang dilakukan dengan tujuan meningkatkan kemampuan literasi disemua muatan pelajaran melalui cara penggunaan buku pengayaan dan strategi membaca di semua muatan pelajaran.

Tahapan tersebut dilaksanakan dengan mempertimbangkan kesiapan masing-masing sekolah. Kesiapan tersebut meliputi kesiapan kapasitas fisik sekolah (ketersediaan fasilitas, sarana, prasarana literasi), kesiapan warga sekolah (siswa, guru, orang tua, dan komponen masyarakat lain), serta kesiapan sistem pendukung lainnya (partisipasi publik, dukungan kelembagaan, perangkat kebijakan yang relevan). Ketiga tahapan tersebut dilaksanakan secara berkelanjutan. 


\section{d.Kemampuan Matematika Siswa}

Menurut Poerwadarminta, (2005: 707) kemampuan berasal dari kata "mampu" yang memiliki arti kesanggupan, kecakapan atau kekuatan. Uno (2008) juga berpendapat bahwa kemampuan adalah merujuk pada kinerja seseorang dalam suatu pekerjaan yang bisa dilihat dari pikiran, sikap, dan perilakunya. Kemampuan matematika dalam penelitian ini maksudnya adalah melihat kecakapan seseorang / siswa ketika menyelesaikan soal atau permasalahan dengan melihat pikiran, sikap, dan perilakunya.

Kemampuan matematika adalah kecakapan yang dimiliki peserta didik untuk memecahkan masalah matematika. Kemampuan tersebut dikelompokkan dalam 3 hal yaitu kemampuan tingkat tinggi, kemampuan tingkat sedang, dan kemampuan tingkat rendah.

\section{e. Pengertian Soal Cerita}

Soal cerita adalah soal yang disajikan dalam bentuk kalimat dalam kehidupan sehari-hari. Soal cerita matematika adalah soal matematika berkaitan dengan kehidupan sehari-hari yang menerapkan prinsip, konsep dan aplikasi dalam matematika. Soal cerita disajikan dalam bentuk lisan maupun tulisan.

\section{f. Langkah-Langkah Penyelesaian Soal Cerita}

Menurut Polya, penyelesaian soal cerita dalam matematika perlu dilakukan sesuai dengan aturan-aturan yang dilakukan untuk menemukan suatu jawaban sebagai hasil temuan untuk memecahkan masalah. Polya (dalam Suherman, 2003:91) juga memberikan empat saran untuk menyelesaikan soal cerita, langkah tersebut meliputi (a) understanding the problem; (b) definising out the plan; (c) carrying out the plan; (d) looking back.

Selain menurut Polya, adapun pandangan menurut Haji (dalam Rohana, 2010:15) ada lima langkah yang digunakan untuk menyelesaikan masalah soal cerita yaitu (a) kemampuan membaca soal; (b) kemampuan menentukan apa yang diketahui dan apa yang ditanyakan pada soal; (c) kemampuan membuat model soal matematika; kemampuan melakukan perhitungan dan (e) kemampuan menentukan jawaban akhir dengan tepat.

\section{Hasil dan Pembahasan}

\section{a. Data Hasil Observasi Pembiasaan GLS}

\section{Tabel Hasil Observasi Pembiasaan GLS di SDN Ketabang}

\begin{tabular}{|c|c|c|c|c|c|c|}
\hline \multirow[t]{2}{*}{ No } & \multirow[t]{2}{*}{ Aspek Pembiasaan GLS } & \multicolumn{5}{|c|}{ Skor } \\
\hline & & 1 & 2 & 3 & 4 & 5 \\
\hline 1 & $\begin{array}{l}\text { Ada kegiatan } 15 \text { menit } \\
\text { membaca (mebaca } \\
\text { dalam hati, } \\
\text { membacakan, membaca } \\
\text { nyaring) yang dilakukan } \\
\text { setia hari (di awal, } \\
\text { tengah, atau menjelang } \\
\text { akhir pelajaran). }\end{array}$ & & & & & $\sqrt{ }$ \\
\hline 2 & $\begin{array}{l}\text { Peserta didik memiliki } \\
\text { jurnal membaca harian. }\end{array}$ & & & & $\sqrt{ }$ & \\
\hline 3 & $\begin{array}{l}\text { Guru, kepala sekolah, } \\
\text { dan/atau tenaga } \\
\text { kependidikan menjadi } \\
\text { model dalam kegiatan } \\
15 \text { menit membaca } \\
\text { dengan ikut membaca } \\
\text { selama kegiatan } \\
\text { berlangsung. }\end{array}$ & & & & & $\sqrt{ }$ \\
\hline 4 & $\begin{array}{l}\text { Ada perpustakaan, sudut } \\
\text { baca di tiap kelas, dan } \\
\text { area baca yang nyaman } \\
\text { dengan koleksi buku } \\
\text { nonpelajaran. }\end{array}$ & & & & $\sqrt{ }$ & \\
\hline 5 & $\begin{array}{l}\text { Ada poster-poster } \\
\text { kampanye membaca di } \\
\text { kelas dan/atau area lain } \\
\text { di sekolah. }\end{array}$ & & & & & $\sqrt{ }$ \\
\hline 6 & $\begin{array}{l}\text { Ada bahan kaya teks } \\
\text { yang terpampang di tiap } \\
\text { kelas. }\end{array}$ & & & $\sqrt{ }$ & & \\
\hline
\end{tabular}


7 Lingkungan sekolah, kantin, dan UKS menjadi lingkungan yang bersih, sehat, dan kaya teks.

8 Sekolah berupaya melibatkan publik (orang tua, alumni, dan elemen masyarakat untuk mengembangkan kegiatan literasi sekolah).

9 Kepala sekolah, guru dan warga sekolah lainnya berkomitmen melaksanakan dan mendukung gerakan literasi sekolah.

10 Kegiatan berjalan secara $\sqrt{ }$ berkesinambungan

b.Data hasil observasi pembiasaan GLS di SDN Kebondalem dapat dilihat pada tabel berikut.

Tabel Hasil Observasi Pembiasaan GLS di SDN Kebondalem

\begin{tabular}{|c|c|c|c|c|c|c|}
\hline \multirow[t]{2}{*}{ No } & \multirow{2}{*}{$\begin{array}{c}\text { Aspek } \\
\text { Pembiasaan GLS }\end{array}$} & \multicolumn{5}{|c|}{ Skor } \\
\hline & & 1 & 2 & 3 & 4 & 5 \\
\hline 1 & $\begin{array}{l}\text { Ada kegiatan } 15 \\
\text { menit membaca } \\
\text { (mebaca dalam } \\
\text { hati, membacakan, } \\
\text { membaca nyaring) } \\
\text { yang dilakukan } \\
\text { setia hari (di awal, } \\
\text { tengah, atau } \\
\text { menjelang akhir } \\
\text { pelajaran). }\end{array}$ & & & & & $\sqrt{ }$ \\
\hline 2 & $\begin{array}{l}\text { Peserta didik } \\
\text { memiliki jurnal } \\
\text { membaca harian. }\end{array}$ & & & & $\sqrt{ }$ & \\
\hline 3 & $\begin{array}{lr}\text { Guru, } & \text { kepala } \\
\text { sekolah, dan/atau } & \\
\text { tenaga } & \\
\text { kependidikan } \\
\text { menjadi model } \\
\text { dalam kegiatan } 15 \\
\text { menit membaca } \\
\text { dengan r ikut } \\
\text { membaca selama } \\
\text { kegiatan } \\
\text { berlangsung. }\end{array}$ & & & & & $\sqrt{ }$ \\
\hline
\end{tabular}

4 Ada perpustakaan, sudut baca di tiap kelas, dan area baca yang nyaman dengan koleksi buku nonpelajaran.

5 Ada poster-poster kampanye membaca di kelas dan/atau area lain di sekolah.

6 Ada bahan kaya teks yang terpampang di tiap kelas.

7 Lingkungan sekolah, kantin, dan UKS menjadi lingkungan yang bersih, sehat, dan kaya teks.

8 Sekolah berupaya melibatkan publik (orang tua, alumni, dan elemen masyarakat untuk mengembangkan kegiatan literasi sekolah).

9 Kepala sekolah, guru dan warga sekolah lainnya berkomitmen melaksanakan dan mendukung gerakan literasi sekolah.

10 Kegiatan berjalan $\sqrt{ }$ secara berkesinambungan

\section{Data Hasil Observasi Pelaksanaan GLS}

Pengambilan data berkaitan dengan pelaksanaan Gerakan Literasi Sekolah dilakukan dengan menggunakan lembar observasi pelaksanaan GLS. Hasil yang diperoleh berdasarkan pengambilan data pelaksanaan GLS di SDN Ketabang dapat dilihat pada tabel berikut. 


\section{Tabel Hasil Observasi Pelaksanaan}

GLS di SDN Ketabang

\begin{tabular}{|c|c|c|c|c|c|c|}
\hline \multirow[t]{2}{*}{$\mathbf{N}$} & \multirow{2}{*}{$\begin{array}{l}\text { Aspek Pelaksanaan } \\
\text { GLS }\end{array}$} & \multicolumn{5}{|c|}{ Skor } \\
\hline & & 1 & 2 & 3 & 4 & 5 \\
\hline 1 & $\begin{array}{l}\text { Ada kegiatan } \\
\text { membaca } \\
\text { (membacakan buku } \\
\text { dengan nyaring, } \\
\text { membaca dalam hati, } \\
\text { membaca bersama, } \\
\text { dan/atau membaca } \\
\text { terpadu) selama } 15 \\
\text { menit diikuti } \\
\text { kegiatan lain dengan } \\
\text { tagihan non- } \\
\text { kademik, seperti } \\
\text { membuat peta cerita } \\
\text { (story map), graphic } \\
\text { organizers, dan } \\
\text { bincang buku. }\end{array}$ & & & & & $\sqrt{ }$ \\
\hline 2 & $\begin{array}{l}\text { Memberikan } \\
\text { penghargaan kepada } \\
\text { capaian perilaku } \\
\text { positif, kepedulian } \\
\text { sosial, dan semangat } \\
\text { belajar peserta didik } \\
\text { (pemberian } \\
\text { penghargaan dapat } \\
\text { dilakukan setiap } \\
\text { pelaksanaan upacara } \\
\text { bendera) secara } \\
\text { berkala. }\end{array}$ & & & $\sqrt{ }$ & & \\
\hline
\end{tabular}

3 Ada kegiatan-

kegiatan akademik

lain yang mendukung

terciptanya budaya

literasi di sekolah

(belajar di kebun,

belajar di lingkungan

luar sekolah, wisata

perpustakaan

kota/daerah dan

taman bacaan

masyarakat, dan lain-

lain)

4 Peserta didik

memiliki portofolio

yang berisi kumpulan

jurnal respon

membaca.

5 Jurnal respon

membaca peserta

didik dipajang di

kelas dan/atau koridor sekolah.

6 Tagihan lisan dan

tulisan digunakan

sebagai penilaian

nonakademik.

7 Perpustakaan, sudut

baca di tiap kelas,

dan area baca yang

nyaman dengan

koleksi buku

nonpelajaran

dimanfaatkan untuk

berbagai kegiatan

literasi.

Data hasil observasi pelaksanaan

GLS di SDN Kebondalem dapat dilihat pada tabel 4.4 berikut.

Tabel Hasil Observasi Pelaksanaan

GLS di SDN Kebondalem

\begin{tabular}{ccccccc}
\hline No & Aspek Pelaksanaan & \multicolumn{5}{c}{ Skor } \\
\cline { 3 - 6 } & GLS & $\mathbf{1}$ & $\mathbf{3}$ & $\mathbf{4}$ & $\mathbf{5}$ \\
\hline $\mathbf{1}$ & Ada kegiatan membaca & & & & & $\sqrt{ }$
\end{tabular}

(membacakan buku

dengan nyaring,

membaca dalam hati,

membaca bersama,

dan/atau membaca

terpadu) selama 15

menit diikuti kegiatan

lain dengan tagihan non-

kademik, seperti

membuat peta cerita

(story map), graphic

organizers, dan bincang

buku.

2 Memberikan

penghargaan kepada

capaian perilaku positif,

kepedulian sosial, dan

semangat belajar peserta

didik (pemberian

penghargaan dapat

dilakukan setiap

pelaksanaan upacara

bendera) secara berkala.

3 Ada kegiatan-kegiatan

akademik lain yang

mendukung terciptanya

budaya literasi di

sekolah (belajar di

kebun, belajar di

lingkungan luar sekolah, 
wisata perpustakaan

kota/daerah dan taman

bacaan masyarakat, dan

lain-lain)

4 Peserta didik memiliki portofolio yang berisi kumpulan jurnal respon membaca.

5 Jurnal respon membaca peserta didik dipajang di kelas dan/atau koridor sekolah.

6 Tagihan lisan dan tulisan digunakan sebagai penilaian nonakademik.

7 Perpustakaan, sudut baca di tiap kelas, dan area baca yang nyaman dengan koleksi buku nonpelajaran dimanfaatkan untuk berbagai kegiatan literasi.

Pengujian korelasi GLS dengan kemampuan menyelesaikan soal cerita matematika di SDN. Ketabang Surabaya

Kriteria pengujian :

$-r_{\text {tabel }} \leq r_{\text {hitung }} \leq r_{\text {tabel }}$, maka Ho diterima.

Membandingkan $r_{\text {hitung }}$ dengan $r_{\text {tabel }}$

$r_{\text {hitung }}(0,517)>r_{\text {tabel }}(0,3291)$.

Pengujian korelasi GLS dengan kemampuan menyelesaikan soal cerita matematika di SDN. Kebondalem Mojokerto

Kriteria pengujian :

$-r_{\text {tabel }} \leq r_{\text {hitung }} \leq r_{\text {tabel }}$, maka Ho diterima.

Membandingkan $r_{\text {hitung }}$ dengan $r_{\text {tabel }}$ $r_{\text {hitung }}(0,667)>r_{\text {tabel }}(0,3739)$.

\section{Kesimpulan}

Terdapat hubungan penerapan GLS dengan kemampua menyelesaikan soal cerita matematika siswa SD kelas V di SDN Kebondalem Mojosari dan SDN. Ketabang Surabaya.

\section{Daftar Acuan}

Astuti, T.P (2014). Perbedaan literasi emergen anak taman kanak-kanak di daerah perkotaan dan pinggiran. Jurnal Psikologi Undip. 13 (02), 107119.

Efendi, Ramlan. 2016. Model Pembelajaran SQ3R untuk mengembangkan kemampuan literasi matematis siswa. Jurnal Pendidikan Matematika. Vol.1, No.2, November 2016. Halaman 109.

Moeleong, Lexy. 2002. Metode Penelitian Kualitatif. Bandung: Remaja Rosda Karya.

Mujib,

Ahmad.

2016. http://wikipendidikan.blogspot.co.id/ 2016/03/pengertian-definisi-maknaliterasi.html

PAUD-DIKMAS. (2016, 12 April). Gerakan Indonesia Membaca: Menumbuhkan Budaya Membaca. Diunduh di http://www.paudduikmas.kemdikbud. go.id/berita/8459.html

Rahim, F. (2008). Pengajaran Membaca di Sekolah Dasar. Jakarta:Bumi Aksara

Sakti, Trenggono Pujo. (2012). Budaya Literasi Sebgai Relasi Dunia: Bentuk Kolonialisme Budaya, "Makalah Seminar Internasional Multikultural dan Globalisasi. UI 12-13 Desember 2012, 258-274.

Sugiyono. 2010. Metode Penelitian Pendidikan Pendekatan Kuantitatif, Kualitatif, dan R\&D. Bandung: Alfabeta. _ 2010. Statistika untuk Penelitian. Bandung: Alfabeta.

Tim Penulis. (2014). Pembelajaran Literasi KelasAwal di LPTK. Jakarta: USAID. 